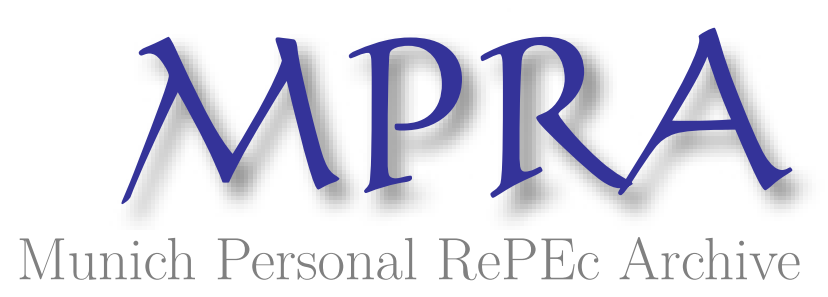

\title{
A Preliminary Contemporary Panel Data Analysis of the Consumption Impact of Cigarette Taxation
}

Cebula, Richard

Jacksonville University

17 April 2010

Online at https://mpra.ub.uni-muenchen.de/49201/

MPRA Paper No. 49201, posted 21 Aug 2013 19:59 UTC 
Richard J. Cebula*

Walker/Wells Fargo Endowed Professor in Finance, Jacksonville University, Davis College of Business, Jacksonville, Florida 32211 - USA

\title{
A Preliminary Contemporary Panel Data Analysis of the Consumption Impact of Cigarette Taxation
}

\begin{abstract}
The adverse health effects from cigarette smoking account for an estimated 400,000 deaths annually in the U.S. Given this circumstance, the present study has two objectives. First, using a panel data set for a very recent time frame, it seeks to investigate the impact of federal plus state cigarette excise taxes (along with the influence of other factors) on the aggregate consumption of cigarettes. The study adopts a five-year state-level panel data series spanning the period 2002 through 2006. Consistent with certain previous studies, the estimates in this study find that the higher the cigarette excise tax, the lower the aggregate volume of cigarettes consumed. However, this outcome does not address the practical problem of the substitution of high nicotine cigarettes for low nicotine cigarettes in light of a significant cigarette tax hike. This circumstance leads to the second objective of this study, namely, to formally propose a general form/template for a cigarette excise tax that is tied directly to each cigarette brand's nicotine and tar content.
\end{abstract}

Keywords - Cigarette smoking per capita, cigarette excise taxation, nicotine and tar-based tax system

7EL classification codes - I18, H20, H70

\section{Introduction}

The use of cigarette excise taxes as a source of revenue for state and local governments remains a pertinent issue [WHITE, 2010]. This is especially the case during recent years when the poorly performing economy has cut into the flows of tax collections needed to finance government outlays. Indeed, New York has increased its cigarette excise tax to the highest in the nation [WHITE, 2010, p. 1007], raising the question «Will high taxes makes smok-

*E-mail:rcebula@ju.edu; fax: +904 2567467; tel: +904 3798086

The author is indebted to Phil DeCicca, Bill Evans, Matt Farrelly, Diana Lien, and Mike Lovernheim. 
ers quit?» [Cox, 2010, p. 1005]. At some level, since the tax increase in New York «...was part of an emergency budget measure to help plug a $\$ 9.2$ billion deficit» [WHITE, 2010, p. 1007], elected officials presumably hope not. Moreover, cigarette smoking, cigarette excise taxes, and the impact of the latter on the former remain a major public policy issue because the adverse health effects resulting from cigarette smoking account for in excess of 400,000 deaths in the U.S. annually [CENTERS FOR DISEASE CONTROL AND Prevention, 2008; 2009]; moreover, cigarette smoking is linked to a host of other adverse health effects [U.S. Department of Health and Human Services, 2001, 2004].

The impact of excise taxes on cigarette consumption has been studied extensively. The usual finding is that higher taxation of cigarettes leads to a reduction in the number of packs of cigarettes consumed [KOCH - CEBULA, 1992; Evans - Farrelly, 1998; Showalter 1998, Chaloupka - WARnER, 2000; FORSTER - JONES, 2001; FARRELly, et al, 2004; LiEN - EvANS, 2005; Adda - Cornaglia, 2006; White, 2010; Cebula, Smith - AlexanDER, 2010]. Typically, it is argued that the higher price on cigarettes in light of higher cigarette taxation acts as a deterrent to smoking. It in fact has been argued that hikes in this excise tax can for some persons make cigarettes 'too costly', such that it reduces consumption by certain current smokers on the one hand while acting as a deterrent to at least some would-be or actual 'new' smokers on the other hand. Oftentimes, when studies find higher excise taxes on cigarettes to reduce the aggregate amount/volume of cigarette consumption, it is also suggested/speculated that such taxation yields social benefits in terms of improving the health status of the population. In this light, cigarette excise taxation takes on relevance not only as a 'sin tax' but also appears to assume the role of a valuable tool to deter smoking in adults as well as young people and thereby improve public health (while simultaneously generating tax revenues for states and other governmental units).

This preliminary panel data study has two objectives. First, it seeks to investigate, using a recent data set, the impact of cigarette excise taxes (federal plus state combined and, alternatively, state-level only) on aggregate cigarette consumption within a context that allows for the influence of a number of other, i.e., non-excise-tax, factors on cigarette smoking as well. The study adopts a five-year state-level panel data series spanning the period 2002 through 2006. Thus, the empirical evidence is relatively current/contemporary. Not surprisingly, consistent with most previous related studies, the empirical evidence in this study (in the form of a variety of specifications) finds that the higher the cigarette excise tax (whether state plus federal or just state), the lower the aggregate volume of cigarettes consumed. This finding, which does not address the practical problem of increased smoking intensity in the form of substitution of higher nicotine cigarettes for lower nicotine 
cigarettes in light of a significant cigarette tax hike [EVANS - FARRELLY, 1998; FARRELLY, et al., 2004]. This phenomenon leads to the second objective of this study, namely, to offer an explicit, practical proposal for a cigarette excise tax that is tied directly to each cigarette brand's nicotine and tar content. Of course, to what extent such a nicotine and tar-based tax, referred to here as an SSET (selective supplementary excise tax) would address the problem of increased smoking intensity in its other form, i.e., increased smoking intensity resulting from increased nicotine consumption from each cigarette smoked [ADDA - CORNAGLIA, 2006] remains to be seen, although it logically should help to address the phenomenon of substituting higher nicotine for lower nicotine cigarettes in the event of a large increase in the cigarette excise tax.

\section{Background}

A number of studies have explored determinants of cigarette consumption; a few are briefly considered here. For instance, Anderson and Mellor [2008] find that risk aversion is significantly associated with cigarette smoking, heavy drinking, being overweight or obese, and seat belt non-use, as well as with several summary measures of risky behavior. The results in the Anderson and Mellor [2008] study suggest, among other things, that individuals in many cases tend to be risk-averse when it comes to cigarette smoking and their health.

Raising cigarette excise taxes is commonly regarded as one of the most effective prevention and control strategies for reducing and/or limiting aggregate cigarette consumption; indeed, it has been thusly regarded for many years [DRAYTON, 1972]. In a study by Lien - Evans [2005], reductions in smoking by pregnant women and subsequent improvements in birth weight occur almost immediately after a large cigarette tax hike has been implemented. A study by Forster - Jones [2001] measures tax elasticities of cigarette consumption. Elasticity estimates are all within the range of -.4 to -.7 , indicating that, for example, an increase in the cigarette tax of $10 \%$ would lead to a decrease in the smoking population of between $4 \%$ and $7 \%$.

A more recent study by Cebula, Smith and Alexander [2010] provides a log-log estimate focusing only on state-level cigarette excise taxation in which the excise tax elasticity of cigarette smoking is found to be negative (0.228 ). In this study, there is evidence that states as a whole can raise state cigarette excise taxes and find said policy to be a fruitful revenue source. Similar results are found in Meier and Licari [1997], Showalter [1998], Lovenheim [1998], Evans and Farrelly [1998], Forster and Jones [2001], Farrelly, et al. [2004], and Lien and Evans [2005].

The Koch and Cebula [1992], Anderson and Mellor (2008), and Cebula, 
Smith, and Alexander [2010] studies also find that the inclination towards cigarette smoking is an increasing function of the age of the population, whereas Koch and Cebula [1992], and Cebula, Smith, and Alexander [2010] argue and find that cigarette consumption is an increasing function of alcohol consumption and unemployment. It is also argued and/or found by Koch and Cebula [1992], Forster and Jones [2001], Anderson and Mellor [2008], Cebula, Smith, and Alexander [2010], and others that the greater the average educational attainment level among the adult population and the higher the per capita income level, the lower the aggregate consumption rate of cigarettes. Naturally, it is expected, based both on micro-economic theory and a number of empirical studies that cigarette consumption is a decreasing function of the price per pack of cigarettes, ceteris paribus. Next, there is a potential role of 'moral hazard' in cigarette smoking behaviors, as suggested in effect in the studies by Koch - Cebula [1992], Anderson - Mellor [2008] and Cebula, Smith, and Alexander [2010]. In particular, health insurance partly insulates individuals from the health problems smoking can create by reducing the risk associated with smoking through allowing access to healthcare and mitigating the individual smoker's financial burden from any smoking-related illness or illnesses. Consequently, health insurance coverage might potentially increase the likelihood of a risk-averse individual's smoking, ceteris paribus; alternatively, in theory, the absence of health insurance may act to discourage smoking among risk-averse individuals. Indeed, the Cebula, Smith, and Alexander [2010] study finds preliminary evidence of this hypothesis, namely, that the higher the percentage of the population without health insurance, the lower the percentage of the population that does not smoke.

Other studies have also found a significant reduction in the total quantity of cigarettes consumed in response to higher cigarette excise taxes; however, according to certain of these studies, smokers often-times respond to the higher cigarette tax by increasing 'smoking intensity'. For example, recent studies by Evans and Farrelly [1998] and Farrelly, et al. [2004] find cigarette smokers switching to cigarettes with a higher tar and nicotine content; this is one form of increased smoking intensity. A more recent study by Adda and Cornaglia [2006] finds that smokers compensate for increases in cigarette excise taxes in two ways, both of which are detrimental to the smoker's health. First, many smokers adjust by reducing the number of packs of cigarettes smoked in the aggregate and then substituting smaller volumes of cigarettes that are higher in nicotine (and typically higher in tar), which is consistent with Evans and Farrelly [1998] and Farrelly, et al. [2004]. Second, Adda and Cornaglia [2006] find that in the face of higher cigarette excise taxes, there is also a serious health problem resulting from increased smoking intensity resulting from increased nicotine consumption from each cigarette smoked. In other 
words, Adda and Cornaglia [2006] find that in response to higher cigarette taxation, many smokers also smoke cigarettes with greater intensity by increasing their intake of nicotine per cigarette through 'smoking down' the higher nicotine (and tar) cigarettes they do smoke. Smoking down a cigarette involves smoking the cigarette until the maximum amount of tobacco in the cigarette has been consumed; ergo, the latter behavior becomes a de facto second form of increased smoking intensity. Thus, understandably, Adda and Cornaglia [2006, p. 1025] logically «...question the usefulness of excise taxes as a tool to regulate smoking intake, especially as the medical literature has shown that increasing the intensity of smoking is detrimental to health [THUN, et al., 1997]».

Based on the studies by Anderson and Mellor (2008), Adda and Cornaglia [2006], Cebula, Smith, and Alexander [2010], Chaloupka and Warner [2000], Forster and Jones [2001], Koch and Cebula [1992], and Lien and Evans [2005], it is expected that, in theory, smoking is negatively impacted by the absence of health insurance, by higher cigarette excise tax levels, by higher cigarette price levels per pack, by higher income levels, and by a higher level of formal education. It is also expected from the studies summarized above that smoking (along with alcohol consumption) is a 'coping mechanism' for the unemployed and therefore that smoking is more likely to be directly/positively associated with both unemployment and alcohol consumption. Furthermore, smokers who are older on average tend to have a longer history of smoking and thus are likely to be more strongly 'addicted' to cigarette smoking (nicotine) than younger smokers, so that the higher the age of a given population cohort member, the greater the likelihood that said person is a smoker [KoCH - Cebula, 1992; ANderson - Mellor, 2008; Cebula, SMITH, AND ALEXANDER, 2010].

\section{An Eclectic Model}

Based on studies cited and/or briefly summarized above, namely, Anderson and Mellor [2008], Adda and Cornaglia [2006], Cebula, Smith, and Alexander [2010], Chaloupka and Warner [2000], Kenkel, and Mathios [2002], Evans and Farrelly [1998], Farrelly et al. [2004], Forster and Jones [2001], Koch and Cebula [1992], and Lien and Evans [2005], this study adopts an eclectic model of cigarette consumption in which the determination of the annual per capita cigarette consumption in year $t$ in state $j$ is modeled as:

$$
\begin{aligned}
& \log \text { CONS }_{t j}=a_{0}+a_{1} A L C_{t j}+a_{2} I_{N C O M E}+a_{3} \operatorname{NOINSURANCE}_{t j} \\
& +a_{4} \operatorname{TAX}_{t j}+a_{5} \text { UNEMPLOY }_{t j}+a_{6} A G E_{t j}+a_{7} \operatorname{HSEDU}_{t j}+a_{8} \text { CIGPR }_{t j}+{ }_{t}
\end{aligned}
$$


where

$\log C O N S_{t j}=$ the natural $\log$ of cigarette consumption in year $t$ in state $j$, measured as the number of packs of cigarettes purchased annually per capita;

$a_{0}=$ constant term;

$A L C_{t j}=$ the number of gallons of alcohol purchased annually per capita (for drinking purposes) in year $t$ in state $j$;

$I N C O M E_{t j}=$ per capita income in year $t$ in state $j$;

NOINSURANCE $t_{t j}=$ percent of the population without health insurance in year $t$ in state $\mathrm{j}$;

$\mathrm{TAX}_{\mathrm{tj}}=$ average total federal plus state cigarette excise tax per pack in year $t$ in state $j$;

UNEMPLOY $Y_{t j}=$ average percentage unemployment rate of the civilian labor force in year $t$ in state $j$;

$A G E_{t j}=$ median age of the population in year $t$ in state $j$;

$H S E D U_{t j}=$ percent of the population in year $t$ in state $j$ over age 25 that has completed at least a high school degree;

$C I G P R_{t j}=$ the average price of cigarettes in year $\mathrm{t}$ in state $\mathrm{j}$; and $\varepsilon_{t}=$ stochastic error term.

For the interested reader, descriptive statistics are provided in Table 1, whereas the correlation matrix among the explanatory variables in equation [1] is provided in Table 2. As shown in Table 2, overall there is no evidence of serious multicollinearity.

In the eclectic model above, it is expected that:

$a_{1}>0, a_{2}<0, a_{3}<0, a_{4}<0, a_{5}>0, a_{6}>0, a_{7}<0$

The study uses state-level panel data for all 50 states over the period 2002 through 2006, where 2006 is the most recent year for which data for all of the explanatory variables are available. Data were collected for the United States' 50 states (excluding Washington, D.C). The panel least squares (PLS) model was first estimated using the Fixed Effects Model and then estimated using the Random Effects Model. Performing the Hausman Test [phtest (fixed, random) ] revealed a $p$-value $=0.0855$, so that the study adopted the Random Effects Model, i.e., Panel EGLS (cross-section random effects) estimations [KENNEDY, 2003, pp. 305-307], White [1980] are provided. The model is initially expressed in semi-log form rather than in linear form in order to simplify interpretation. The data sources are, as follows:

CONS was obtained from an online version of the 2008 release of Tax Burden on Tobacco, Table 11, which can be found at http://www.tobaccoissues.com/getobject.aspx? folder=root/tobaccoissues/excisetaxes\&name $=$ Taxb urden_2008_vol_43.pdf

The $A L C$ data were obtained from the National Institute on Alcohol 
Tab. 1 - Descriptive Statistics.

\begin{tabular}{|l|c|c|}
\hline Variable & Mean & Standard Deviation \\
\hline CONS & 74.82 & 29.65 \\
\hline ALC & 2.28 & 0.43 \\
\hline INCOME & 23,323 & 3,453 \\
\hline INSURANCE & 14.999 & 4.219 \\
\hline TAX & 104.81 & 52.43 \\
\hline STTAX & 66.88 & 51.86 \\
\hline UNEMPLOY & 5.078 & 1.092 \\
\hline AGE & 36.688 & 2.158 \\
\hline HSEDU & 84.12 & 9.96 \\
\hline CIGPR & 3.04 & 0.53 \\
\hline
\end{tabular}

Tab. 2 - Correlation Matrix among Explanatory Variables in Equation [3]

\begin{tabular}{|c|c|c|c|c|c|c|c|c|}
\hline & ALC & INCOME & NOINSURANCE & TAX & UNEMPLOY & AGE & EDU & CIGPR \\
\hline ALC & 1.0 & & & & & & & \\
\hline INCOME & 0.336 & 1.0 & & & & & & \\
\hline NOINSURANCE & -0.083 & -0.307 & 1.0 & & & & & \\
\hline TAX & 0.105 & 0.454 & -0.229 & 1.0 & & & & \\
\hline UNEMPLOY & -0.200 & -0.190 & 0.235 & -0.004 & 1.0 & & & \\
\hline AGE & 0.326 & 0.223 & -0.296 & 0.182 & -0.283 & 1.0 & & \\
\hline EDU & 0.151 & 0.162 & -0.177 & 0.092 & -0.126 & 0.097 & 1.0 & \\
\hline CIGPR & 0.306 & 0.565 & -0.381 & 0.610 & -0.002 & 0.228 & 0.067 & 1.0 \\
\hline
\end{tabular}


Abuse and Alcoholism (NIAAA) at http://www.niaaa.nih.gov/Resources/ DatabaseResources/QuickFacts/AlcoholSales/consum03.htm

Data for the variable INCOME were obtained from the yearly American Community Survey (ACS) data on Table B19301 at http://factfinder.census.gov/servlet/DatasetMainPageServlet?_program=ACS\&_submenuId= \&_lang=en\&_ts=

The nominal per capita income provided was adjusted to reflect inflation using the GDP deflator from the US Department of Commerce: Bureau of Economic Analysis (BEA), Table 1.1.9. «Implicit Price Deflators for Gross Domestic Product» at http://www.bea.gov/national/nipaweb/SelectTable.asp? Selected $=\mathrm{N}$

The data for the NOINSURANCE variable were obtained from the CDC's Behavioral Risk Factor Surveillance System at http://www.cdc.gov/brfss/ maps/gis_data.htm from the question «Do you have any kind of health care coverage?»

The variable $T A X$ was obtained from the Center for Disease Control (CDC) STATE system using fourth quarter data for each year in the study at http://apps.nccd.cdc.gov/StateSystem/stateSystem.aspx? selectedTopic $=602 \&$ selected Measure $=10005 \& \mathrm{dir}=1$ eg_report $\& u c N a m e=u c l e g s m k-$ freesummaryexcisetax\&year=2006_4\&excel=htmlTable\&submitBk=y

The nominal excise tax $(T A X)$ was adjusted to reflect inflation using the GDP deflator from the BEA, Table 1.1.9. «Implicit Price Deflators for Gross Domestic Product» at http://www.bea.gov/national/nipaweb/SelectTable.asp? Selected $=\mathrm{N}$

It should be observed that the variable $T A X$ is the sum of the federal cigarette excise tax and the state excise tax. Adding these two excise taxes reflects the finding in Showalter [1998, p. 1118] that «Federal excise taxes per se do not appear to be more effective than state excise taxes in terms of reducing cigarette smoking». Thus, we do not differentiate between a penny of federal tax on cigarettes and a penny of state taxes in terms of aggregate cigarette consumption per se.

UNEMPLOY was obtained from the yearly ACS data on Table C23001 at http://factfinder.census.gov/servlet/DatasetMainPageServlet?_program=ACS\&_submenuId=\&_lang=en\&_ts=

$A G E$ and $C I G P R$ were obtained from the yearly ACS data on Table B01002 at http://factfinder.census.gov/servlet/DatasetMainPageServlet?_program=AC S\&_submenuId=\&_lang=en\&_ts=

$\bar{H} S E D U$ was obtained from the yearly ACS data on Table C15002 at http://factfinder.census.gov/servlet/DatasetMainPageServlet?_program=AC S\&_submenuId=\&_lang=en\&_ts=. HSEDU was divided by each state's population to obtain a percentage. 


\section{Initial Empirical Findings}

The Panel EGLS (cross-section random effects) estimation of equation [1] yields:

$$
\begin{aligned}
& \log C O N S_{t j}=4.34+0.209 A L C_{t j}-0.00002 I N C O M E_{t j}-0.012 \text { NOINSURANCE }_{t j} \\
& (+5.02) \quad(-15.49) \quad(-3.38) \\
& -0.00253 T A X_{t j} \\
& (-10.27) \\
& \text { + 0.0096 UNEMPLOY } \text { U }_{j j} 0.0297 A G E_{t j}-0.0009 \text { HSEDU }_{t j}-0.007 \text { CIGPR }_{t j} \\
& \begin{array}{llll}
(+0.94) & (+5.48) & (-7.67) & (-3.48)
\end{array}
\end{aligned}
$$

$R^{2}=0.64$, adjusted $R^{2}=0.62, F=52.49$

where terms in parentheses are $t$-values. All eight of these estimated coefficients on the explanatory variables exhibit the expected signs; seven of the explanatory variables are statistically significant beyond the one percent level, whereas one (for the unemployment rate) fails to be statistically significant at the ten percent level. The $F$-statistic (52.49) is statistically significant at far beyond the one percent level and attests to the robustness of the model. The coefficient of determination $\left(R^{2}\right)$ and adjusted $R^{2}$ indicates that the model explains more than three-fifths of the variation in the dependent variable.

The estimated coefficient on consumption of alcohol $(A L C)$ variable is positive and significant at the one percent level, implying that greater alcohol consumption induces increased cigarette consumption per capita; indeed, this finding could be interpreted as indicating that cigarette smoking and alcohol consumption are complementary goods (Anderson and Mellor, 2008). The coefficient on the real per capita income variable (INCOME) is negative and statistically significant at the one percent level, implying that as income increases, people are less prone to cigarette consumption; thus, cigarettes do not appear to be a 'normal good' because individuals with higher incomes are, on average, less inclined to smoke. The coefficient on the percent of the population with no health insurance variable (NOINSURANCE) is negative and statistically significant at the one percent level. This result can probably be attributed to 'moral hazard': those without health insurance are less likely to smoke because they cannot afford the pecuniary costs of the health complications smoking implies.

The coefficient on the unemployment rate variable (UNEMPLOY) is positive but not statistically significant at the ten percent level. This result is contrary to our expectations, which were for a positive and significant coefficient, 
given that smoking can be viewed as a coping mechanism for unemployed persons. The coefficient for the median age variable $(A G E)$ is also positive and significant at the one percent level, indicating that older Americans are either more likely to smoke, or smoke more frequently than their younger counterparts, perhaps at least in part because they have been exposed to cigarette smoking over a longer period and are potentially more strongly addicted to the nicotine. The educational variable (HSEDU), has a negative coefficient that is statistically significant at the one percent level, indicating that those who have a higher level of educational attainment (in this case, completion of at least a high school education), are less likely to smoke, or will smoke fewer packs than their less educated counterparts. The estimated coefficient on the cigarette price per pack $(C I G P R)$ is, as one would expect, negative and statistically significant: higher prices elicit reduced aggregate consumption of cigarettes per capita.

The coefficient on the federal plus state cigarette excise tax variable $(T A X)$ is negative and statistically significant at the one percent level. This indicates that the higher the cigarette excise tax, the lower the aggregate consumption of cigarettes per capita. Of course, through substitution of higher nicotine (and typically higher tar) cigarettes for cigarettes with lower levels of nicotine and tar in order to reduce the pecuniary cost of smoking due to higher excise taxation, there is no evidence that the total amount of nicotine and tar consumed has necessarily been diminished. Indeed, it could be argued that it is possible that the consumption of nicotine and tar (and carbon monoxide) from smoking cigarettes has been redistributed to some degree from those who no longer smoke because of the higher cigarette tax to those who smoke more intensively because of the higher cigarette tax.

As both a reality check and a check of robustness, equation [1] is now reestimated after substitution of the average state excise tax per pack in year $\mathrm{t}$ in state $\mathrm{j}\left(S T T A X_{t j}\right)$ for $T A X_{t j}$ Given the uniformity of the federal cigarette excise tax, the results should be nearly identical to those found in equation [3]. This Panel EGLS (cross-section random effects) estimation is provided in equation [4]:

$$
\begin{aligned}
& \log C_{O N S_{t j}}=4.2+0.208 A L C_{t j}-0.00002 I N C O M E_{t j}-0.012 \text { NOINSURANCE }_{t j} \\
& \begin{array}{lll}
(+5.09) & (-15.63) \quad(-3.40)
\end{array} \\
& -0.00257 \text { STTAX } \\
& (-10.40) \\
& \text { + 0.0011 UNEMPLOY } Y_{t j}+0.029 A_{G E_{t j}} 0.0009 \text { HSEDU }_{t j}-0.0065 \text { CIGPR }_{t j} \\
& \text { (+1.03) } \\
& \text { (+5.19) } \\
& \text { (-7.50) } \\
& R^{2}=0.64, \text { adjusted } R^{2}=0.63, F=52.95
\end{aligned}
$$


The results in the estimation in [4] are nearly identical to those in the estimation in [3] above. Thus, all of the estimated coefficients exhibit the expected signs, with all statistically significant with the expected signs at the one percent level, except (once again) for the unemployment rate, which fails to be statistically significant at even the ten percent level. Thus, the aggregate consumption of cigarettes per capita is once again found to be positively a function of alcohol consumption and age, while being a decreasing function of income, the absence of health insurance, educational attainment, cigarette prices, and of course cigarette excise taxation. Of greatest relevance is the latter, i.e., the result for the state tax cigarette excise tax variable, which is nearly identical is magnitude to that for the total cigarette excise tax per pack (state plus federal) and also is again statistically significant at far beyond the one percent level. Cigarette excise taxes appear to reduce aggregate cigarette consumption. Based on the results in equations [3] and [4], a one cent cigarette excise tax appears to reduce the aggregate number of cigarettes consumed per capita by $0.25-0.26$ percent.

\section{Additional Empirical Findings}

This section of the study has two components. The first consists of additional Panel EGLS (cross-section random effects) estimates to verify the consistency and robustness of the results in the model. The second consists of Panel Two Stage EGLS (cross-section random effects) estimates that allow for the possible simultaneity bias that may result from the contemporaneousness of the dependent variable (cigarette consumption per capita) and the price per pack of cigarettes.

\section{Additional Panel EGLS (Cross-Section Random Effects) Estimates}

Estimating the basic model specified in equation [1] in linear form yields results that are qualitatively compatible with those shown in the semi-log estimates in equations [3] and [4]. This Panel EGLS (cross-section random effects) estimate is provided in column (a) of Table 3 . As shown in this estimation, all of the estimated coefficients exhibit the expected signs; furthermore, six of the aforementioned coefficients are statistically significant at the one percent level and one is statistically significant at the five percent level, with the coefficient for variable UNEMPLOY once again failing to be significant at the ten percent level. Of greatest relevance to the present study is the negative and statistically significant coefficient on the $T A X_{t j}$ variable: it is negative and statistically significant at far beyond the one percent level, 
affirming our results in equations [3] and [4], albeit that the model is estimated in a different, i.e., linear, form. In addition to this specific confirmation of our findings above, the findings for the remaining variables are also consistent with those above.

As further tests of the basic model, two additional estimates are provided; these can be found in columns (b) and (c) of Table 3. In all cases, the results are completely compatible with those in equations [3] and [4] above. In sum, then, this contemporary panel data set yields Panel EGLS (cross-section random effects) results that imply consistently that: one the one hand, the per capita consumption of cigarettes in the U.S. is inversely related to income, the absence of health insurance, the price per pack of cigarettes (without counting taxes thereupon), the level of educational attainment, and the level of the cigarette taxation; on the hand, the aggregate per capita consumption of cigarettes in the U.S. is directly related to age and per capita alcohol consumption.

Taken in conjunction with the findings provided in equations [3] and [4], the results shown in columns (a), (b, and c) indicate a robust pattern of relationships between per capita cigarette consumption and a variety of economic and non-economic variables. Among these Panel EGLS (cross-section random effects) results, that which is most pertinent is the negative relationship between cigarette consumption per capita and total federal plus state cigarette excise tax levels, where the estimated coefficient remains remarkably consistent in magnitude (and statistical significance) across several specifications.

\section{Panel Two Stage EGLS (Cross-Section Random Effects) Estimates}

In the model as developed thus far, the dependent variable (cigarette consumption per capita) and the explanatory variable CIGPR (the average price per pack of cigarettes) are treated as contemporaneous. This situation implies the possibility of simultaneity bias in the estimates provided above [KENNEDY, 2003, Ch. 10]. To address this possible problem, the analysis next provides Panel Two Stage EGLS (cross-section random effects) estimates. The instrumental variable for the variable CIGPRtj is $P O V t-1 j$, the one year lag of the percent of the population in state $j$ that was classified as being at 125 percent of the poverty level or below. The choice of instrument is based on the finding that $\log (C I G t j)$ and POVt-1j are highly correlated with one another whereas $P O V t-1 j$ is uncorrelated with the error terms in the system.

The Panel Two Stage EGLS (cross-section random effects) estimate of the full model is provided in column (a) of Table 4. In column (a), all eight of the estimated coefficients exhibit the expected signs, with seven being sta- 
Table 3 - Additonal Estimates.

\begin{tabular}{|c|c|c|c|}
\hline $\begin{array}{l}\text { Dependent Variable: } \\
\text { Constant }\end{array}$ & $\begin{array}{l}\text { (a) } \\
C O N S_{t j} \\
86.97\end{array}$ & $\begin{array}{l}\text { (b) } \\
\log C O N S_{t j} \\
4.41\end{array}$ & $\begin{array}{l}\text { (c) } \\
\log C O N S_{t j} \\
4.45\end{array}$ \\
\hline$A L C_{t j}$ & $\begin{array}{l}-18.9 * * \\
(-4.76)\end{array}$ & $\begin{array}{l}0.2075^{* *} \\
(5.08)\end{array}$ & ------- \\
\hline$I N C O M E_{t j}$ & $\begin{array}{l}-0.0014 * * \\
(-5.58)\end{array}$ & $\begin{array}{l}-0.00002 * * \\
(-7.41)\end{array}$ & $\begin{array}{l}0.00002 * * \\
(5.43)\end{array}$ \\
\hline NOINSURANCE $E_{t j}$ & $\begin{array}{l}-1.024 * * \\
(-3.71)\end{array}$ & $\begin{array}{l}-0.0118^{* *} \\
(-3.52)\end{array}$ & $\begin{array}{l}-0.013 * * \\
(-3.38)\end{array}$ \\
\hline$T A X_{t j}$ & $\begin{array}{l}-0.16^{* *} \\
(-8.84)\end{array}$ & $\begin{array}{l}-0.00252^{* *} \\
(-10.45)\end{array}$ & $\begin{array}{l}-0.00254 * * \\
(-9.92)\end{array}$ \\
\hline$U N E M P L O Y_{i j}$ & $\begin{array}{l}0.43 \\
(0.50)\end{array}$ & ------- & ------- \\
\hline$A G E_{t j}$ & $\begin{array}{l}1.807 * * \\
(7.76)\end{array}$ & $\begin{array}{l}0.0289 * * \\
(4.50)\end{array}$ & $\begin{array}{l}0.341 * * \\
(5.24)\end{array}$ \\
\hline$H S E D U_{t j}$ & $\begin{array}{l}-0.058^{* *} \\
(-7.25)\end{array}$ & $\begin{array}{l}-0.00088 * * \\
(-7.35)\end{array}$ & $\begin{array}{l}-0.00089 * * \\
(-5.33)\end{array}$ \\
\hline$C I G P R_{t j}$ & $\begin{array}{l}-0.543^{*} \\
(-2.00)\end{array}$ & $\begin{array}{l}-0.0064 * * \\
(-3.41)\end{array}$ & $\begin{array}{l}-0.0048^{*} \\
(2.05)\end{array}$ \\
\hline $\begin{array}{l}R^{2} \\
\operatorname{adj} R^{2} \\
\quad F\end{array}$ & $\begin{array}{l}0.48 \\
0.46 \\
27.68 * *\end{array}$ & $\begin{array}{l}0.64 \\
0.63 \\
60.07 * *\end{array}$ & $\begin{array}{l}0.61 \\
0.60 \\
64.21 * *\end{array}$ \\
\hline
\end{tabular}

Terms in parentheses are t-values. ${ }^{* *}$ indicates statistically significant at the $1 \%$ level; *indicates statistically significant at the $5 \%$ level.

tistically significant at the one percent level and one statistically significant at the two percent level. The $F$-ratio (29.99) is statistically significant at the one percent level, attesting to the overall strength of the model.

As these results show, the cigarette smoking per capita variable is an increasing function of the alcohol consumption and age variables, which are both statistically significant at the one percent level, and the unemployment 
rate, which is statistically significant at the two percent level. Unlike the earlier estimates in this study, the UNEMPLOY variable now is not only positive but also statistically significant, perhaps reflecting our conjecture that smoking may be a coping mechanism for at least some of those persons who are unemployed.

The cigarette smoking variable also is a decreasing function (in all cases statistically significant at the one percent level) of income, the absence of

Table 4 - Panel Two Stage EGLS (Cross-Section Random Effects) Estimates

\begin{tabular}{|c|c|c|}
\hline \multicolumn{2}{|c|}{ Dependent Variable: $\log C O N S_{t j}$} & $\begin{array}{l}\text { (b) } \\
\log C O N S_{t j} \\
4.28\end{array}$ \\
\hline$A L C_{t j}$ & $\begin{array}{l}-0.234 * * \\
(-5.97)\end{array}$ & $\begin{array}{l}0.227 * * \\
(4.91)\end{array}$ \\
\hline$I N C O M E_{t j}$ & $\begin{array}{l}-0.00002 * * \\
(-6.87)\end{array}$ & $\begin{array}{l}-0.00003 * * \\
(-7.11)\end{array}$ \\
\hline NOINSURANCE $E_{t j}$ & $\begin{array}{l}-0.011^{* *} \\
(-3.09)\end{array}$ & $\begin{array}{l}-0.0103^{* *} \\
(-3.05)\end{array}$ \\
\hline$T A X_{t j}$ & $\begin{array}{l}-0.00243 * * \\
(-6.98)\end{array}$ & $\begin{array}{l}-0.00244 * * \\
(-7.47)\end{array}$ \\
\hline$U N E M P L O Y_{t j}$ & $\begin{array}{l}0.0166^{*} \\
(2.36)\end{array}$ & ------- \\
\hline$A G E_{t j}$ & $\begin{array}{l}0.032 * * \\
(11.12)\end{array}$ & $\begin{array}{l}0.0309^{* *} \\
(8.32)\end{array}$ \\
\hline$H S E D U_{t j}$ & $\begin{array}{l}-0.0008^{* *} \\
(-3.59)\end{array}$ & $\begin{array}{l}-0.00076^{* *} \\
(-3.75)\end{array}$ \\
\hline$C I G P R_{t j}$ & $\begin{array}{l}-0.008 * * \\
(-3.48)\end{array}$ & $\begin{array}{l}-0.0061 * * \\
(-2.74)\end{array}$ \\
\hline$F$ & $29.99 * *$ & $33.75 * *$ \\
\hline
\end{tabular}

Terms in parentheses are t-values. ${ }^{*}$ indicates statistically significant at the $1 \%$ level; ${ }^{*}$ indicates statistically significant at the $5 \%$ level. 
health insurance, the price per pack of cigarettes (without counting taxes thereupon), the level of educational attainment, and the level of the cigarette taxation. Regarding the magnitude of the cigarette tax effect, the estimated coefficient is -0.00243 , which is nearly identical to the Panel EGLS (crosssection random effects) estimate results discussed earlier in this study.

Finally, as a test of robustness of the results in column (a) of Table 4, a second estimate is now provided. In this estimate [Table 4, column (b)], the unemployment rate has been dropped from the system; this action is based on the notion that the unemployment rate was not statistically significant in the Panel EGLS (cross-section random effects) estimates. Clearly, the findings revealed by the Panel Two Stage EGLS (cross-section random effects) estimate in column (b) are entirely consistent with the results in column (a). Thus, the evidence for robust and consistent results is very strong.

\section{Summary and Perspective}

This study in part effectively provides updated confirmation of a number of earlier studies that had found cigarette consumption to be negatively a function of the level of cigarette excise taxation. In particular, using a state-level panel data series for the period 2002-2006, the estimations in this study consistently find an inverse relationship between the number of packs of cigarettes consumed per capita and the level of federal plus state cigarette excise taxes.

But how strong is this effect? In the semi-log estimates in this study, the average value for the estimated coefficient on the cigarette excise tax variable is -0.0025 . Thus, it would appear that a one cent tax increase would presumably reduce total cigarette consumption by about $0.25 \%$. Observe, then, that if politicians were truly serious about reducing cigarette consumption in the aggregate, imposing an across-the board (all states) uniform simultaneous increase in the excise tax on cigarettes (or, arguably, such a tax increase imposed by the federal government) of $\$ 1.00$ per pack could potentially create a scenario in which aggregate cigarette consumption could be approximately reduced [in theory] by one-fourth, i.e., by $25 \%{ }^{1}$. Thus, large [by historical standards] cigarette excise tax increases can accomplish both significant reductions in total cigarette consumption while adding to the coffers of the governmental unit or units imposing the increased excise tax.

1 To put this $\$ 1.00$ tax hike in perspective, some years ago Evans and Farrelly [1998, p. 578 ] had noted that «...different proposals have called for federal tax hikes of up to $\$ 2.00$ per pack». 
Consider now in more detail the effect implied by the empirical findings in this study, based on recent data, namely, that raising cigarette taxes reduces per capita cigarette consumption in the aggregate, a finding consistent with studies of earlier periods and other types of data-sets [MEIER - LICARI, 1997; ShOWALTER, 1998; LOVENHEIM, 1998; EvanS - FARRELly, 1998; ForSTER - JoNES, 2001; FARrelly, et al., 2004; LiEN - Evans, 2005]. Consider in particular that, in response to a significant increase in the cigarette excise tax, there undoubtedly would be a reduction in smoking by some current smokers, as well as a likely reduction in the growth rate of potential new (often youth) smokers. Presumably, many of the aforementioned would substitute other commodities and/or increased saving for cigarette consumption.

However, by contrast, consider the extent to which many smokers continue to smoke but respond to the tax hike by engaging in more smoking intensive behaviors such as 'smoking cigarettes down', i.e., increased smoking intensity resulting from increased nicotine consumption from each cigarette smoked, resulting from smoking down to the very last accessible tobacco in each cigarette smoked [ADDA - CORNAGLIA, 2006]. Alternatively, consider those who, although they may smoke fewer cigarettes numerically speaking, respond to higher cigarette taxation by changing smoking behavior to one of substituting cigarettes with higher nicotine (and, typically, higher tar) for cigarettes with lower nicotine (and typically lower tar), in effect, increasing smoking intensity in a different way. Such behaviors imply that the net health benefits to society of significantly across-the-board increased excise taxes on cigarettes will not be so great as they may seem at first glance [EVANS - FARRELLY, 1998; ADDA - CORNAGLIA, 2006]. Indeed, the net public health effect of increasing the cigarette excise tax could conceivably even be zero or negative [EVANS - FARRELLY, 1998].

\section{A Nicotine and Tar Based Cigarette Tax}

Given these conclusions, this study now explicitly provides an explicit tax policy proposal/ recommendation that may help to offset the shifts smokers make to higher nicotine cigarettes and to more smoking intensive behaviors. In particular, as an alternative to simply levying a large, uniform cigarette excise tax increase on all cigarette brands, this study proposes that policymakers could choose to also target the higher nicotine and higher tar cigarettes by imposing a selective supplementary excise tax (or simply SSET) in addition to a large flat excise tax per pack, which is consistent with the observation by Evans - Farrelly [1998, p. 578] that a useful cigarette «...tax might be based on the tar and nicotine content of cigarettes». Plausible forms of such a tax are provided below, in equations [5] and [6]. Before considering 
said tax proposals, the issue of what level of government should impose the tax warrants a few observations.

For example, assume a reasonable alternative to the present system of cigarette excise taxes is deemed potentially very beneficial in reducing not only cigarette consumption but also in promoting public health, i.e., in addressing the smoking intensity issues. Assume next that it is left to the states to administer such a tax system (SSET). If some states were to resist raising cigarette excise taxes in the form of the SSET or were to resist raising the cigarette excise tax in the same way and to the same extent, due either to the influence of tobacco producers, tobacco lobbyists, and/or tobacco growers organizations and/or due to some other reason, whereas other states raised the taxes by fully adopting the optimal SSET, the benefits for the policy would be less extensive, particularly in those cases where cigarette purchases could be made on a large scale across state lines without significant transaction costs [CHILES SOLLARS, 1993; LOVENHEIM, 2008]. Interestingly, on this very issue, Lovenheim [2008, p. 7] estimates that 13-25 percent of consumers purchase cigarettes in border localities. Thus, as Lovenheim [2008, p. 7] suggests, cross-border smuggling would confound much of the potential health as well as revenue benefits from increased cigarette excise taxes imposed by state governments unless all of the states agreed to adopt the exact same SSET at the very same time. That is, for the cigarette excise tax at the state level to yield large public health benefits, a very significant degree of co-operation and co-ordination between states on cigarette excise tax policy would be necessary in order to get them all to adopt not only an SSET but the same SSET. Given that historically there has been and continues to be an enormous interstate variation in state-imposed cigarette excise tax levels and given the historical differences among the states in the predisposition of state legislatures and governors to tax tobacco products, the likelihood of a uniform large cigarette SSET imposed by all of the states would seem remote at best. Ergo, it is argued that the administration of the SSET, once its precise form is identified, would very likely, out of practical necessity, lie with the federal government. Alternatively stated, whereas the opportunity for successful adoption of either some form of nicotine-based cigarette excise tax and/or nicotine-plus-tar based cigarette excise tax in the public interest appears to be plausible, it is likely that the only feasible way to impose a both significant and geographically uniform such tax would be at the federal level ${ }^{2}$.

\footnotetext{
${ }^{2}$ It is not impossible that such an effort could be at least partly offset by states that choose to reduce state cigarette excise taxation in an effort to decrease effects of the total taxation increase imposed by the federal government; on the other hand, given the revenue-poor status of most states in recent years, it may be unlikely or is at least questionable that such an effort would gather much support.
} 
Accordingly, consider what a federally administered, modified taxing of cigarettes might look like, i.e., the practical/plausible form of the federal selective supplementary excise tax, or simply federal SSET. In addition to a large flat federal tax on all cigarettes per pack, this approach could involve constructing a supplementary tax increase in direct proportion to each cigarette brand's nicotine and tar content. For example, the total federal excise tax (TFET) could have two variable components in addition to a general flat tax applicable to all cigarette brands equally:

TFET $=$ FLATTX $+n j$ NICOTINEj $+t j$ TARj

where TFET $j$ is the total federal excise tax on cigarette brand $j$, which consists of FLATTX, a flat federal excise tax imposed on every pack of cigarettes regardless of nicotine and tar content, and [nj NICOTINEj + tjTARj], the selective supplementary excise tax (SSET) on brand $j$. The tax rates $n j$ and $t j$ correspond to pennies per pack. Clearly the magnitudes of $n j$ and $t j$ must be sufficiently large in magnitude as to impose a clear financial disincentive to consume cigarette $j$.

In taxing cigarette brand $j$, a reference point is needed both in terms of nicotine and tar. The reference points for the nicotine and tar tax bases suggested here are 0.1 milligrams $(0.1 \mathrm{mg})$ of nicotine and 1.0 milligram $(1 \mathrm{mg})$ of tar. Thus, if cigarette brand $j$ had $0.4 \mathrm{mg}$ of nicotine, the numerical value of the term NICOTINEj = 4; furthermore, if cigarette $j$ had, say, $6.0 \mathrm{mg}$ of $\operatorname{tar}, T A R j=6$. Although obviously other reference points could be chosen, these two reference points not only manifest the virtue of simplicity but also effectively correspond to the lowest nicotine and tar cigarettes on the U.S. market ${ }^{3}$.

Thus, in this initial formulation - equation [5] and using the reference points suggested above, the SSET would impose higher taxes on cigarettes in direct proportion to the amounts of both nicotine and tar contents [taxation would be proportional to nicotine and tar contents]. The SSET tax rates would be so constructed that a cigarette with $0.2 \mathrm{mg}$ of nicotine carries twice the nicotine SSET as a cigarette containing only $0.1 \mathrm{mg}$ of nicotine; alternatively, a cigarette with $1.0 \mathrm{mg}$ of nicotine would carry a nicotine SSET of ten times that of the cigarette with only $0.1 \mathrm{mg}$ thereof. As for the tar SSET, it would work the same way. Thus, a cigarette with $2 \mathrm{mg}$ of tar would carry a $\operatorname{tar} S S E T$ twice that of a cigarette having $1 \mathrm{mg}$ of tar.

\footnotetext{
${ }^{3}$ For instance, based on the concentration of tar in a cigarette, very low tar cigarettes contain $7 \mathrm{mg}$ or less of tar, low tar cigarettes contain more than $7 \mathrm{mg}$ of tar but less than 15, medium-tar cigarettes contain 15 to $21 \mathrm{mg}$ of tar, and high-tar cigarettes contain at least $22 \mathrm{mg}$ of tar.
} 
In addition, the proposed tax shown in [5] could be expressed in non-linear form and be made progressive with respect to either a cigarette's nicotine, tar, and/or carbon monoxide contents. For instance, the tax bases NICOTINEj and /or TARj could be expressed with an exponent greater than 1 and thereby introduce graduated taxation, which arguably would create greater disincentives to consume cigarettes with higher nicotine, tar, and/ or CO contents, depending upon which tax base (s) has its (their) exponents > 1 . Thus, the general form of the SSET is given by:

TFETj $=F L A T T X+n j$ NICOTINEj $j^{a}+t j T A R j^{b}$

where $F L A T T X \geq 0, n j \geq 0, t j \geq 0, a=0$ or $a \geq 1, b=0$ or $b \geq 1$

A policy as exemplified in [6] above could be useful in promoting health benefits from cigarette excise tax policy by discouraging substitution of high nicotine cigarettes for lower nicotine cigarettes in light of significantly increased cigarette excise taxation. It remains to be seen to what extent greater smoking intensity behavior resulting from increased nicotine consumption from each cigarette smoked, as described in Adda and Cornaglia (2006), would be ameliorated, however.

Interestingly, the studies by Gine, Karlan - Zinman [2010] and O'Connor, et al. [2011] suggest certain behavioral-based policy possibilities that, from the perspective of this study, could be used to supplement the SSET policy route (de facto 'third degree excise tax discrimination') in an effort to reduce cigarette consumption and truly promote improved public health. Moreover, a recent study by Anderson, Foster, and Frisvold [2010] finds compelling evidence that certain public policies for the young may be effective in reducing the growth of new smokers. Based on their empirical analysis, Anderson, Foster, and Frisvold [2010, p. 587] find that «...participation in Head Start reduces the probability than an individual smokes cigarettes as a young adult». Thus, endeavors such as Head Start, which is a comprehensive childhood development program, could also be used in conjunction with, i.e., to supplement, the SSET.

Certainly, there is much need for and much room for further research into the issue at hand. Included in the list of questions to be investigated is the magnitude of the terms included in the general equation [4], namely, FLAT$T X, n j, t j, a$, and $b$. Clearly, more aggressive tax policies could take the form of not only of higher values for $n j$ and/or $t j$ but also the form of progressive taxation through imposing values for $a$, and/or $b$ in excess of 1 . In this age of controversial efforts to achieve health care reform, there clearly is an urgency underlying genuinely serious public policy change regarding cigarette excise tax policy. The work must continue with haste and care, given the social and private costs of lost human life and other health conditions result- 
ing from cigarette smoking, as observed in the Introduction above. Finally, it is perhaps worth observing that the cigarette excise template described above could be easily modified to apply to cigarette consumption deterrence in any nation, not merely in the U.S.

\section{REFERENCES}

Anderson, L. R. - Mellor, J. M., 2008, «Predicting Health Behaviors with an Experimental Measure of Risk Preference», Fournal of Health Economics, 27 (4): 126074.

Adda, J. - Cornaglia, F., 2006, «Taxes, Cigarette Consumption, and Smoking Intensity», The American Economic Review, 96 (4): 1013-28.

Cebula, R.J. - Smith, K.E. - AlEXANDER, G.M., 2010, «The Impact of State Cigarette Taxes on Cigarette Consumption: Recent Evidence», State Tax Notes, 56 (26): 2143-50.

Centers for Disease Control and Prevention, 2008, «Morbidity and Mortality Weekly Report», http://www.cdc.gov/mmwr/preview/mmwrhtml/ mm5745a3.htm

Centers for Disease Control and Prevention, 2009, «Health, United States, 2009», http://www.cdc.gov/nchs/data/hus/hus09.pdf

Chaloupka, F. J. - Warner, K. E., 2000, «The Economics of Smoking», in Anthony J. Culver and Joseph P. Newhouse, eds., Handbook of Health Economics, Amsterdam: Elsevier Science, North-Holland: 1539-627.

Chiles, T.W. - Sollars, D.L., 1993, «Estimating Cigarette-Tax Revenue», fournal of Economics and Finance, 17 (3): 1-15.

Cox, R.A., 2010, «Will High Taxes Make Smokers Quit?», State Tax Notes, 56 (13): 1005-6.

Drayton, W., 1972, «The Tar and Nicotine Tax: Pursuing Public Health Through Tax Incentives», The Yale Law Review, 81 (8): 1487-1516.

Evans, W. N. - Farrelly, M. C., 1998, «The Compensating Behavior of Smokers: Taxes, Tar, and Nicotene», RAND fournal of Economics, 29 (3): 578-95.

Farrelly, M. C. - NimsCH, C. T. - Hyland, A. and Cummings, K. M., 2004, «The Effects of Higher Cigarette Prices on Tar and Nicotine Consumption in a Cohort of Adult Smokers», Health Economics, 13 (1): 49-58.

Forster, M. - Jones, A. M., 2001, «The Role of Tobacco Taxes in Starting and Quitting Smoking: Duration and Analysis of British Data», Fournal of Royal Statistical Society, 164 (3): 517-47.

Gine, XavieR; K., D. - Zinman, J., 2010, «Put Your Money Where Your Butt Is: A Commitment Contract for Smoking Cessation», America Economic fournal: Applied Economics, 2 (4): 213-35.

Holt, C. A. - LAurY, S. K., 2002, «Risk Aversion and Incentive Effects», The American Economic Review, 92 (5): 1644-55.

Kennedy, P., 2003, A Guide to Econometrics, $5^{\text {th }}$ ed., Cambridge, MA: M.I.T. Press. 
Koch, J. V., 1992, «A Note on Smoking Health Costs and Public Policy», American fournal of Economics and Sociology, 41 (2): 159-60.

LiEn, D. S. - Evans, W. N., 2005, «Estimating the Impact of Large Cigarette Tax Hikes: The Case of Maternal Smoking and Infant Birth Weight», The fournal of Human Resources, 40 (2): 373-92.

Lovenheim, M.F., 2008, «How Far to the Border? The Extent and Impact of Cross-Border Casual Cigarette Smuggling», National Tax fournal, 61 (1): 7-32.

MeIER, K.J. - LiCARI, M.J., 1997, «The Effect of Cigarette Taxes on Cigarette Consumption», American Fournal of Public Health, 87 (7): 1126-30.

O'Connor, R.J - Norton, K.J. - Bansal-Travers, M. - Mahoney, M.C. - CumMINGS, K.M. and BorlaND, R., 2011, Harm Reduction fournal, 8 (1): 1-8.

Showalter, M.H., 1998, «The Effect of Cigarette Taxes on Cigarette Consumption», American Fournal of Public Health, 88 (7): 1118-9.

Thun, M. J. - Lally, C. A. - Flannery, J. T. - Calle, E. E. - Flanders, W. D. and Heath, C. W. Jr., 1997, «Cigarette Smoking and Changes in the Hystopathology of Lung Cancer», Fournal of the National Cancer Institute, 89 (21): $1580-86$.

U.S. Department of Health and Human Services, 2004, The Health Consequences of Smoking: A Report of the Surgeon General, Atlanta, GA: U.S. Department of Health and Human Services, Office on Smoking and Health. http://www/tobacco/data_statistics/sgr/sgr_2004/index.htm

U.S. Department of Health and Human Services, 2001, Women and Smoking: A Report of the Surgeon General, Rockville, MD: U.S. Department of Health and Human Services, Public Health Service, Office of the Surgeon General. http://www/tobacco/data_statistics/sgr/sgr_2001/index.htm

White, H., 1980, «A Heteroskedasticity-Consistent Covariance Matrix and a Direct Test For Heteroskedasticity», Econometrica, 48 (4): 817-38.

White, N. M., 2010, «New York Governor Approves Highest Cigarette Tax in Nation», State Tax Notes, 56 (13): 1007. 